\title{
Photoinduced Charge-Transfer Association of Tetracyanoquinodimethane with Aminobiphenyls
}

\author{
Yong Hee Kim," Sang-Don Jung, Myung-Ae Chung, Ki Dong Song, and Dae Won Cho \\ Department of Chemistry: Chosth Linversity, Gwangit 501-759, Korea. ${ }^{*}$ E-mall awchoachosunac.kr \\ IT Comergence Research Laboratorv, ETRI, Daejeon 305-700, Korea \\ Received March 8, 2008
}

\begin{abstract}
The molecular association of acceptors with electron donors is studied in the highly-polar solvent $\mathrm{CH}_{3} \mathrm{CN}$. Tetracyanoquinodimethane (TCNQ) forms a stable charge-transfer complex with donor molecules such as 4aminobiphenyl (4-AB), benzidine (BD) and 2-aminobiphenyl (2-AB) with high association constants. The complexes of TCNQ with 4-AB or BD show new absorption bands at around 800 and $500 \mathrm{~nm}$. which can be identified as reduced TCNQ ${ }^{-}$and $\mathrm{TCNQ}^{--}$species. respectively. These bands grow quickly upon photoirradiation, implying that the charge-transfer complexes are easily formed in an excited state. Conversely. a small spectral manifestation of the charge transfer was observed in the case of $2-\mathrm{AB}$ complex. It is demonstrated that the structural orientation between the geminate ion pairs could play an important role in building a stable complex
\end{abstract}

Key Words : Photoinduced electron transfer, 7,7'8,8'-Tetracyanoquinodimethane (TCNQ), 4-Aminobiphenyl. 2-Aminobiphenyl, Benzidine

\section{Introduction}

The charge-transfer complexes originating from the interaction between an electron donor and acceptor molecules in bimolecular equilibriums have been an important research topic in physical chemistry and biochemistry over the past decades. ${ }^{1-4}$ The charge-transfer sy stems in molecular optoelectronic devices such as molecular-based transistors. wires. and rectifiers. or in the doping of organic semiconducting polymers. are currently important issues in materials science ${ }^{5-8}$ For instance $7,7^{\prime} 8.8^{\prime}$-tetracyanoquinodimethane (TCNQ) has been widely used as a strong electron acceptor to form highly conducting charge-transfer complexes.-1: Since the first report of the tetrathiafulvalene/TCNQ complex as an "organic metal" in 1973. a number of subsequent studies related to charge-transfer complexes have been reported.$^{13}$ Especially, the partial para-magnetism and electrical conductivity of TCNQ has received a significant amount of attention. ${ }^{1+}$ To this end one of the more prevalent strategies for the preparation of electro-magnetically novel materials is the reaction of electron donors (including amine compounds) with electron acceptors (such as TCNQ) to generate semi-conducting or superconducting complexes. Another teclunique is the enhancement of conductivity due to the doping of ionic species or mineral acids. ${ }^{15}$
Aromatic amines such as 4-aminobiphenyl (4-AB). 2 aminobiphneyl (2-AB), and benzidine (BD) are well-known chemical carcinogens. ${ }^{16.17}$ It has been suggested that these aromatic amines are likely to be more mutagenic due to their relative ease of oxidation. as oxidation has been considered a primary step of the mutagenic process. ${ }^{18.19}$ However. it has also been reported that the mutagenicity of aromatic amines does not entirely correlate with their oxidation potentials..$^{\text {2" }}$ implying that the mutagenic process through charge transfers can be affected by factors other than the oxidation potential.

To demonstrate how oxidative aminobiphenyl derivatives play a critical role in the mutagenic process through electron transfers. this study focuses on the redox behavior of the TCNQ acceptor for the following reasons: TCNQ is a planar $\pi$-acceptor with reversible redox potentials in a reasonable reduction potential $\left(E_{\text {ret }}^{v}\right)$ range. and the reduced TCNQ is stable in solution and can be rigorously characterized via isolation as a pure crystalline. It should be noted that the driving-force contribution $\left(\Delta G_{E T}^{o}\right)$ is the primary factor for interpreting the formation of a charge-transfer complex. The charge-transfer complex fonmation is ascribed to interaction of the electron-poor $\pi$-orbital system of the acceptor with the electron-rich $\pi$-orbitals of the donor. Thus, charge-transfer complex fonnation can be affected by the orientation of
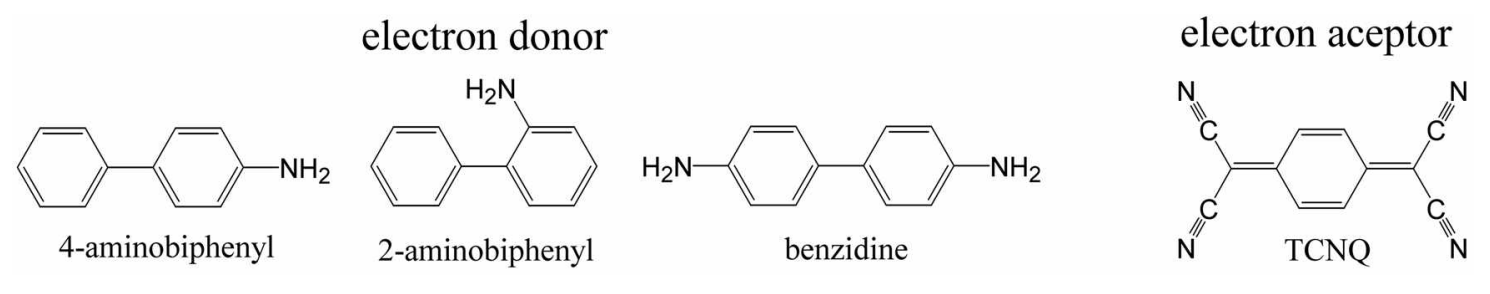

Scheme 1 
the $\pi$-orbital interaction between the donor and acceptor molecules. This paper presents in detail the charge-transfer complexes of TCNQ with three aninobiphenyl derivatives having different $\pi$-conjugations, as shown in Scheme 1 . Subsequent electronic absorption measurement of the systems is used to investigate the molecular association in terms of charge-transfer interaction.

\section{Experimental Section}

TCNQ. 4-AB and 2-AB were purchased from Aldrich $\mathrm{Co}$. and $\mathrm{BD}$ purchased from Fluka $\mathrm{Co}$. All aninobiphenyl derivatives were purified using recrystallization in ethanol. In the case of TCNQ, the chenical was further purified by a sublimation technique at $210^{\circ} \mathrm{C} . \mathrm{CH}_{3} \mathrm{CN}$ (Merck, HPLC degree) was then used to prepare the solutions. The concentration of the electron acceptor TCNQ was fixed, and the concentration of the donor molecules was controlled through the addition of a stock solution. In brief, the same volume of TCNQ stock solution was added to a different volume of donor stock solution, thereby keeping the total volume constant so that the concentration of TCNQ would remain constant $\left(2 \times 10^{-5} \mathrm{M}\right)$ through variation in the donor concentration.

The absorption spectra were recorded with a Shimadzu UV-3101PC spectrophotometer. Because the formation of charge-transfer complexes occurs slowly in a ground state. the spectra of each solution were measured after storage for 6 days in the dark, intercepting the light. In this case, the absorption spectra on $\mathrm{TCNQ} /$ donors complexes did not change anymore. These solutions show the stability for months under the room temperature and room-light condition. The absorption measurement for kinetics of photoinduced charge transfer complexes was performed using on a spectrophotometer (Myungin Crystec Co. MPDS-1024) with a 1024-channel photodiode array detector, making it possible to obtain on-line spectra during photoirradiation (light source: $70 \mathrm{~W}$ tungsten-halogen lamp).

\section{Results and Discussion}

Charge-transfer complex between TCNQ and 4-aminobiphenyl. Figure 1 shows the absorption spectra of the $\mathrm{TCNQ} / 4-\mathrm{AB}$ complex in $\mathrm{CH}_{3} \mathrm{CN}$. The development of a broad band at around $500 \mathrm{~nm}$ was conconitant with a decrease of the neutral TCNQ band at $400 \mathrm{~nm}$ and an anion radical of TCNQ (TCNQ') band at around $840 \mathrm{~nm}:{ }^{11,22}$ the absorption band at $500 \mathrm{~nm}$ was attributed to dianion TCNQ $\left(\mathrm{TCNQ}^{2}\right)^{21.22}$ Two structural bands for TCNQ ${ }^{-2}$ at 740 and $840 \mathrm{~nm}$ grew gradually according to an increase of the 4-AB concentration (Figure 1. inset), but the absorption intensity reduced again in a high concentration of $4-\mathrm{AB}$ of over $4 \times$ $10^{-5} \mathrm{M}$ (Figure 2). The isosbestic point was observed at around $420 \mathrm{~lm}$. indicating an equilibrium between the TCNQ. TCNQ- and $\mathrm{TCNQ}^{-}$species. It seems that the fonnation of the 1:1 and 2:1 inclusion conplexes between the TCNQ and 4-AB processes were stepwise vio the

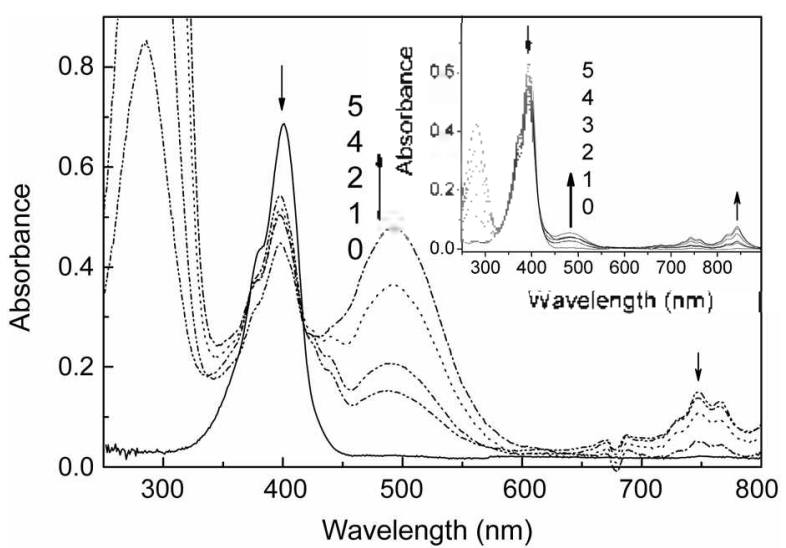

Figure 1. Absorption spectra of the mixtures of TCNQ $\left(2 \times 10^{-5}\right.$ M) and $4-\mathrm{AB}$ in $\mathrm{CH}_{3} \mathrm{CN}$. Concentration of donor molecule in $(0)(0$; (1) $4 \times 10^{-5}:(2) 8 \times 10^{-5} ;(4) 1.6 \times 10^{-4} ;$ and $(5) 2.0 \times 10^{-4} \mathrm{M}$, respectively. Inset figure absorption spectra are measured at a low concentration of $4-\mathrm{AB}$ in (0) $0:(1) 4 \times 10^{-i},(2) 8 \times 10^{-i} ;(3) 1.2 \times$ $10^{-5}$ (4) $1.6 \times 10^{-5}$; and (5) $2.0 \times 10^{-5} \mathrm{M}$, respectively.

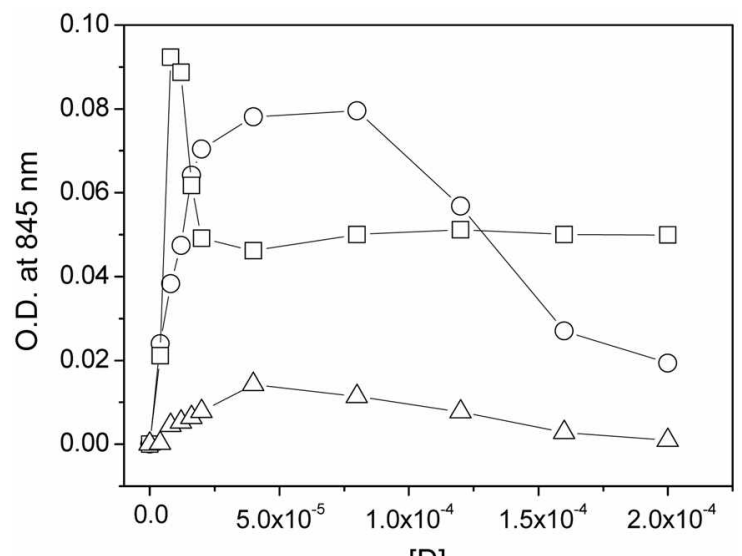

[D]

Figure 2. (A) Absorbance change of $\mathrm{TCNQ}{ }^{-}$monitored at $845 \mathrm{~nm}$ in presence of donor molecules $\left(0-2.0 \times 10^{-1} \mathrm{M}\right)$ in $\mathrm{CH}_{3} \mathrm{CN}$ : $(\vdots) 4-$ $\mathrm{AB},(\hat{-}) \mathrm{Bz}$, and $(\sqsubset) 2-\mathrm{AB}$.

following two equilibriums:

$$
\begin{gathered}
\mathrm{TCNQ}+\mathrm{D} \rightleftharpoons\left(\mathrm{TCNQ}^{-*} / \mathrm{D}^{+*}\right), K_{1} \\
\left(\mathrm{TCNQ}^{-\cdot} / \mathrm{D}^{+*}\right)+\mathrm{D} \rightleftharpoons\left(\mathrm{TCNQ}^{2-} / 2 \mathrm{D}^{+*}\right) \cdot K_{2}
\end{gathered}
$$

where the $1: 1 \mathrm{TCNQ}^{-} / 4-\mathrm{AB}^{-*}$ complex is formed with TCNQ at a low concentration of $4-\mathrm{AB}$ of below $4 \times 10^{-5} \mathrm{M}$. Then, the $1: 1 \mathrm{TCNQ}^{-} / 4-\mathrm{AB}^{-*}$ complex is consecutively converted to $\mathrm{TCNQ}^{--} / 2 \mathrm{D}^{-*}$ in the high concentration range of $4-\mathrm{AB}$.

Figure 3 shows the plot of absorbance (Abs.) as a function of donor (D, 4-AB) concentration according to the classical Benesi-Hildebrand equation ${ }^{23}$ for the $\mathrm{D}+\mathrm{A} \rightleftharpoons \mathrm{DA}$ equilibrium.

$$
\frac{[A]}{A b s}=\frac{1}{\varepsilon}+\frac{1}{\varepsilon K[D]}
$$

Eq. (1) allows for an estimation of the complex formation constant $K$ and the apparent extinction coefficient $\varepsilon$ at a given absorption wavelength of the donor-acceptor (DA) complex. In Eq. (3). the complex DA only absorbs at 

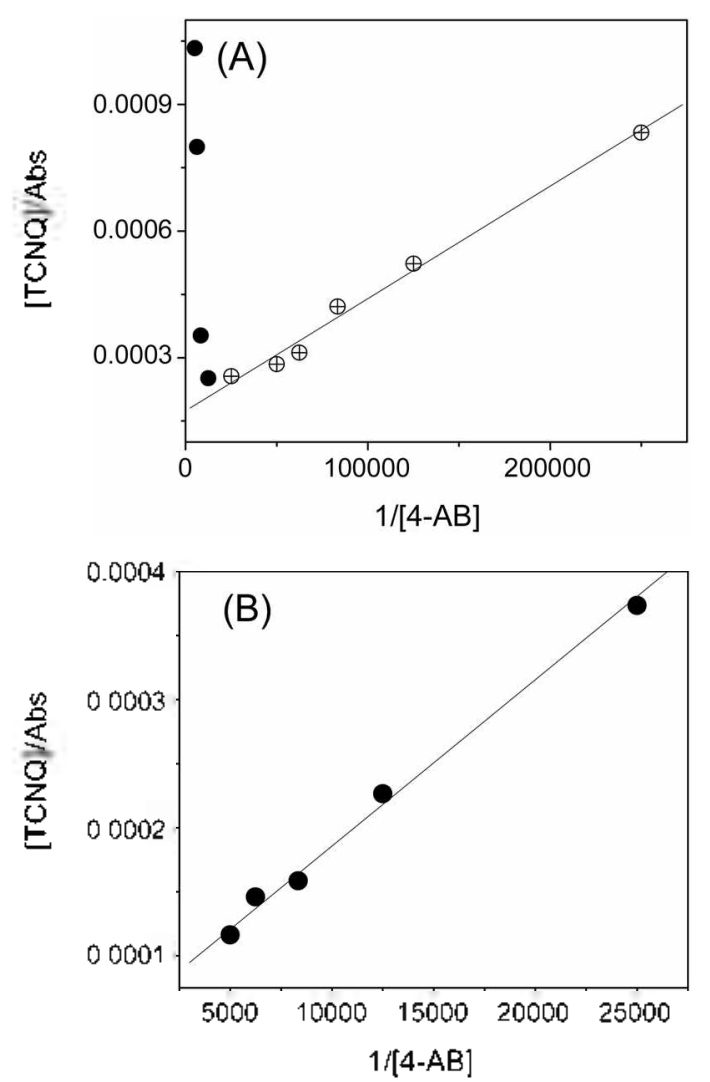

Figure 3. Benesi-Hilderbrand plot of $\mathrm{TCNQ} / 4-\mathrm{AB}$ in $\mathrm{CH}_{3} \mathrm{CN}$ : the absorbance changes are monitored at $845 \mathrm{~cm}$ (A) and $500 \mathrm{~cm}$ (B). In order to calculate the formation constant, $K_{2}$, the initial concentration of $\left[\mathrm{TCNQ}^{\circ}\right]$ is assumed to be identical to [TCNQ] at over $4 \times 10^{-5} \mathrm{M}$ of $4-\mathrm{AB}$.

monitoring wavelengths such as 500 or $840 \mathrm{~nm}$; thus. $\varepsilon$ is identical to $E_{\mathrm{D} A}$. In a low concentration of $4-\mathrm{AB}$, the plots of the inverse of the optical density in the region of the absorption of $\mathrm{TCNQ}^{-}$as a function of $1 /[4-\mathrm{AB}]$ are linear. thereby allowing the calculation of the complex formation constants. This result implies that the stoichiometry of the association is $1: 1$ in a low concentration of $4-\mathrm{AB}$. The $K_{1}$ values for the TCNQ complexes are listed in Table 1 .

From the slope and its intercept of the first linear curve monitored at $845 \mathrm{~nm}$. as shown in Figure 3. the formation constant of the $1: 1 \mathrm{TCNQ}^{-*} / 4-\mathrm{AB}^{-*}$ complex $K_{1}$ was determined to be $65,100 \pm 5,200 \mathrm{M}^{-1}$. which is large enough for a strong interaction of TCNQ with $4-\mathrm{AB}$. In addition, from the linear curve monitored at $500 \mathrm{~nm}$ the formation constant of the $1: 2 \mathrm{TCNQ}^{-1} /\left(4-\mathrm{AB}^{--}\right)$c complex $K$, was deternined to be ca. $4,300 \pm 300 \mathrm{M}^{-1}$, which is much smaller than for $K_{1}$.

Table 1. Complex formation constants and extinction coefficients for the electron donor (4-AB, 2-AB or BD) and acceptor (TCNQ) complexes in $\mathrm{CH}_{3} \mathrm{CN}$

\begin{tabular}{lccc}
\hline & TCNQ/4-AB & TCNQ/BD & TCNQ/2-AB \\
\hline $\mathrm{K}_{1}\left(\mathrm{M}^{-1}\right)$ & $65,100 \pm 3,200$ & $\sim 258,000$ & nd \\
$\mathrm{K}_{2}\left(\mathrm{M}^{-1}\right)$ & $4,300 \pm 300$ & $6,200 \pm 100$ & $1,900 \pm 40$ \\
$\log c_{1}\left(\mathrm{M}^{-1} \mathrm{~cm}^{-1}\right)$ & $3.76 \pm 0.04$ & - & - \\
$\log \varepsilon_{2}\left(\mathrm{M}^{-1} \mathrm{~cm}^{-1}\right)$ & $4.25 \pm 0.05$ & $4.36 \pm 0.04$ & $4.12 \pm 0.09$ \\
\hline
\end{tabular}

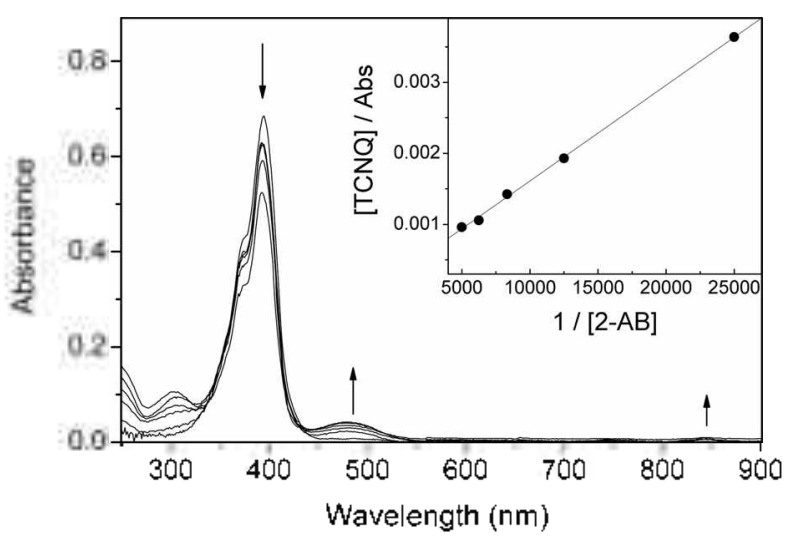

Figure 4 . Electronic absorption spectra of the mixtures of TCNQ $\left(2 \times 10^{-5} \mathrm{M}\right)$ and $2-\mathrm{AB}$ in $\mathrm{CH}_{3} \mathrm{CN}$; concentration of donor molecule in $(0) 0 ;(1) 4 \times 10^{-5} ;(2) 8 \times 10^{-5} ;(3) 1.2 \times 10^{-4},(4) 1.6 \times$ $10^{-4}$ and (5) $2.4 \times 10^{-4} \mathrm{M}$, respectively. Inset: Benesi-Hilderbrand plot of $\mathrm{TCNQ} / 2-\mathrm{AB}$ in $\mathrm{CH}_{3} \mathrm{CN}$, the absorbance changes are monitored at $500 \mathrm{~nm}$.

This is in good accordance with our suggestion for consecutive equilibrium reactions.

Charge-transfer complex between TCNQ and 2-aminobiphenyl. A small absorption change in the $\mathrm{TCNQ} / 2-\mathrm{AB}$ complex was observed. as shown in Figure 4. The complex fomation constant for $\mathrm{TCNQ}^{-1} / 2 \cdot \mathrm{AB}^{++}$was hard to determine. because of very low absorbance at $845 \mathrm{~mm}$ : however, the plot obtained at $500 \mathrm{~mm}$ according to $\mathrm{Eq}$. (3) is linear (Figure 4, inset). The complex formation constant of $1: 2$ $\mathrm{TCNQ}^{-1} /\left(2-\mathrm{AB}^{+*}\right)$ is smaller than for other complexes. indicating that the association of the $\mathrm{TCNQ} / 2-\mathrm{AB}$ complex is weak compared to other systems.

In addition, spectral change in the TCNQ/2-AB system was comparatively small. The fact that the oxidation potential (Tables 2 and 3 ) of $2 \cdot \mathrm{AB}$ is comparable with other donors was initially surprising, though subsequent consideration of the orientation between the donor and acceptor molecules described below verified that this result was hardly anomalous. The dihedral angle between two phenyl moieties of $2-A B$ is 85 degrees. as calculated using a semiempirical calculation (PM3 method). due to the steric hindrance of the amino group. The dihedral angles of $4-\mathrm{AB}$ and $\mathrm{BD}$ were each calculated to be about 47 degrees. with corresponding absorption bands observed around 281 and $287 \mathrm{~nm}$. respectively. indicating that the $\pi$-conjugations

Table 2. Half-wave redox potential and Gibbs tree energies $(\Delta G)$ for photoinduced electron-transfer processes in electron donor (4$\mathrm{AB}, 2-\mathrm{AB}$ or $\mathrm{BD}$ ) and acceptor (TCNQ) systems in $\mathrm{CH}_{3} \mathrm{CN}$

\begin{tabular}{lcccc}
\hline & $\begin{array}{c}E_{\alpha x}(\mathrm{~V})^{a} \\
\text { r. SCE }\end{array}$ & $\begin{array}{c}E_{r e d}(\mathrm{~V})^{b} \\
\text { r.S. SCE }\end{array}$ & $\begin{array}{c}E_{00} \\
(\mathrm{eV})^{c}\end{array}$ & $\begin{array}{c}\Delta G_{p t} \\
(\mathrm{eV})\end{array}$ \\
\hline TCNQ & - & 0.17 & 3.10 & - \\
4-AB & 0.69 & - & - & -2.58 \\
2-AB & 0.79 & - & - & -2.48 \\
BD & $0.36,0.63$ & - & - & $-2.91^{d},-2.64^{d}$ \\
\hline
\end{tabular}

"values were from ref. 20 . "values were from ref. 26 and 27 . values were from ref. 21 . "The values of $\mathrm{BD}$ denote the first and second oxidation potentials. 
Table 3. Half-wave redox potential and Gibbs free energies ( $\Delta G$ ) for photoinduced electron-transter processes in electron donor (4$\mathrm{AB}, 2-\mathrm{AB}$ or $\mathrm{BD}$ ) and acceptor (TCNQ ${ }^{-}$) sy stems in $\mathrm{CH}_{3} \mathrm{CN}$

\begin{tabular}{lcccc}
\hline & $\begin{array}{c}E_{o r}(\mathrm{~V})^{a} \\
\text { v. SCE }\end{array}$ & $\begin{array}{c}E_{\text {rez }}(\mathrm{V})^{b} \\
\text { v. SCE }\end{array}$ & $\begin{array}{c}E_{\text {(p) }} \\
(\mathrm{eV})^{c}\end{array}$ & $\begin{array}{c}\Delta G_{\text {es }} \\
(\mathrm{eV})\end{array}$ \\
\hline $\mathrm{TCNQ}^{*}$ & - & -0.37 & 1.46 & - \\
$4-\mathrm{AB}$ & 0.69 & - & - & -0.40 \\
$2-\mathrm{AB}$ & 0.79 & - & - & -0.30 \\
$\mathrm{BD}$ & $0.36,0.63$ & - & - & $-0.73^{d},-0.46^{d}$ \\
\hline
\end{tabular}

"values were from ref. $20{ }^{b}$ values were from ref. 26 and $27 .{ }^{c}$ values were from ref. $21 .{ }^{d}$ The values of $\mathrm{BD}$ denote the first and second oxidation potentials.

were extended. However, the absorption maximum of 2-AB appeared at $225 \mathrm{mu}$ with a shoulder around $250 \mathrm{~mm}$. likely due to the interruption of electronic communication between the two phenyl mojeties. Although 2-AB has a comparable oxidation potential as either $4-\mathrm{AB}$ or $\mathrm{BD}$, the interaction of TCNQ with 2-AB is weak, showing only a small change of absorption at 845 or $500 \mathrm{~nm}$. This result implies that ion paring between TCNQ and 2- $\mathrm{AB}$ is not favorable because of the structural inhibition of the $\pi \cdot \pi$ interaction. Based on these findings. it can be further inferred that the $\pi-\pi$ interaction plays an important role in the formation of chargetransfer complexes using planar organic donors and acceptor molecules.

Charge-transfer complex between TCNQ and benzidine. Figure 5 shows absorption spectra of $\mathrm{TCNQ} / \mathrm{BD}$ complex in $\mathrm{CH}_{3} \mathrm{CN}$. TCNQ ${ }^{-}$is generated in applying very low concentration of $\mathrm{BD}$ as shown in Figure 2. The absorption intensity for the $\mathrm{TCNQ}^{-}$complex at $845 \mathrm{~nm}$ grows quickly even in a concentration of $2 \times 10^{-5} \mathrm{M}$ (Figure 2). This means that the association between TCNQ and BD is very strong. Actually, the $K_{1}$ for $\mathrm{TCNQ}^{-*} / \mathrm{BD}^{--}$obtained at $845 \mathrm{~nm}$ is quite large, $-258.000 \mathrm{M}^{-1}$. compared to the other complexes.

Photoinduced charge-transfer complex formation. Photoinduced charge-transfer complex formation was investi-

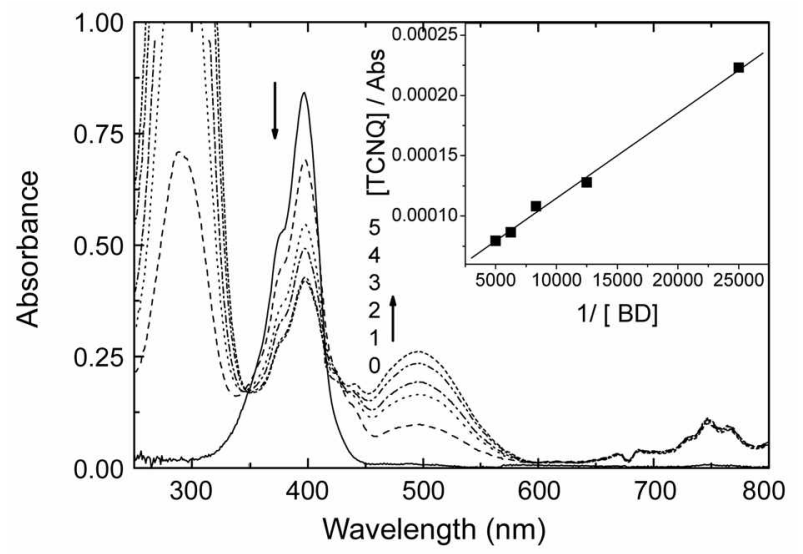

Figure 5. Electronic absolption spectra of the mixtures of TCNQ $\left(2 \times 10^{-5} \mathrm{M}\right)$ and $\mathrm{BD}$ in $\mathrm{CH}_{3} \mathrm{CN}$; concentration of donor molecule in (0) $0 ;(1) 4 \times 10^{-5}:(2) 8 \times 10^{-5}:(3) 1.2 \times 10^{-4}:(4) 1.6 \times 10^{-4}$, and (5) $2.0 \times 10^{-4} \mathrm{M}$, respectively. Inset: Benesi-Hilderbrand plot of TCNQ/BD in $\mathrm{CH}_{3} \mathrm{CN}$, the absorbance changes are monitored at $500 \mathrm{~nm}$.

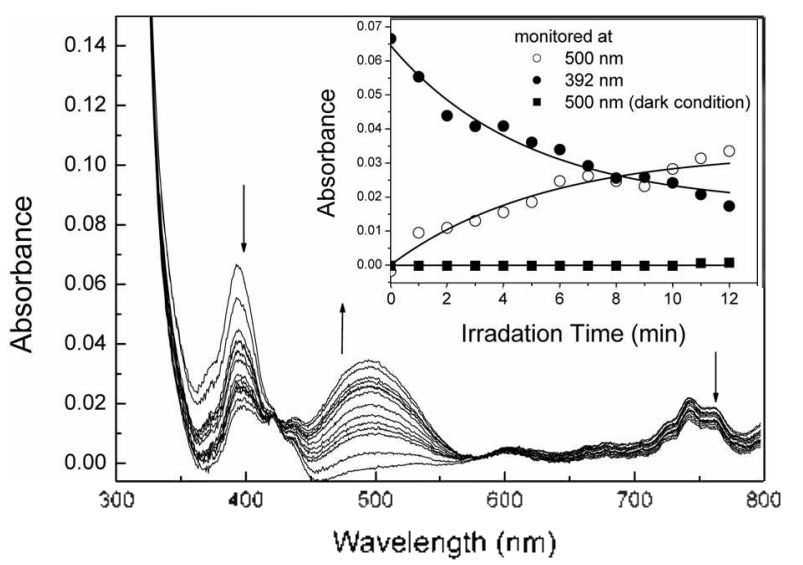

Figure 6. Absorption spectra for the mixture of TCNQ $\left(2 \times 10^{-5}\right.$ $\mathrm{M})$ and $\mathrm{BD}\left(2 \times 10^{-4} \mathrm{M}\right)$ system in $\mathrm{CH}_{3} \mathrm{CN}$ upon photoinadiation. Irradiation interval is 5 min and the light source is a $70 \mathrm{~W}$ tungstenhalogen lamp with a $350 \mathrm{~nm}$ cut-off filter. The measuring time is set at $\mathrm{l} \mathrm{ms}$ to reduce any photoreaction. Inset: kinetic profile monitored at $392 \mathrm{~nm}$ (filled circle) and $500 \mathrm{~nm}$ (open circle). respectively; the bottom line (filled square) denotes a reference measured in a dark condition without irradiation.

gated based on kinetic measurements obtained using absorption spectroscopy. The sample solution was irradiated immediately after mixing of TCNQ $\left(2 \times 10^{-5} \mathrm{M}\right)$ and $\mathrm{BD}(2$ $\times 10^{-4} \mathrm{M}$ ). Upon photoirradiation. a broad band at around $500 \mathrm{~mm}$ developed and was accompanied with a decrease of the TCNQ neutral band at $400 \mathrm{~nm}$. as shown in Figure 6. In the inset of Figure 6. the absorbance of TCNQ ${ }^{2-}$ monitored at $500 \mathrm{~nm}$ grows quickly compared with that stored in a dark room to shield the light. This indicates that charge-transfer complexes easily form via the photoinduced electron-transfer (PET) process in an excited state. Note that though we prepared the $\mathrm{TCNQ} / \mathrm{BD}$ solution with extreme care. the trace absorption band for anion radical of TCNQ (TCNQ') at above $700 \mathrm{~nm}$ could not be completely eliminated. This means that the reduction process of TCNQ occurs easily under weak light.

The likelihood of PET process occurring could be inferred based on the free-energy change $\Delta G$. The $\Delta G$ associated with electron-transfer for the excited singlet state $\left(\mathrm{S}_{1}\right)$ of TCNQ was evaluated using the Relum-Weller equation $(5)^{2-4,25}$

$$
\Delta G_{e r}=F\left(E_{c x}^{\mathrm{a}}-E_{r e d}^{\mathrm{d}}\right)-E_{i \mathrm{ij}}-\frac{e^{2}}{c r}
$$

where $E_{o x}^{i j}$ and $E_{r e d}^{i j}$ are the oxidation and reduction potentials for the donor and acceptor, respectively. These two parameters were obtained earlier using electrochemical measurements. the values of which are in Table 1. Here. $E_{\mathrm{ixI}}$ denotes the lowest excited electronic state where the PET reaction occurs. The final term is the coulombic stabilization term: when the solvent has a large dielectric constant value. e.g. $\mathrm{CH}_{3} \mathrm{CN}(\varepsilon \sim 35.84)$, the Coulomb energy term might be neglected. In our systems. a contribution from the coulombic tern was assigned for $\mathrm{CH}_{3} \mathrm{CN}\left(\hat{e}^{\hat{2}} / \varepsilon r=<0.1 \mathrm{eV}\right)$ and the free energy calculation was employed. The $\Delta G$ values for PET between TCNQ and the aminobiphenyls are presented in 
Table 1 . The negative values of $\Delta \mathrm{G}(\Delta \mathrm{G}<0)$ clearly iniply that PET from the donors to TCNQ is exothermic and energetically probable in an excited state.

\section{Conclusion}

The acceptor TCNQ reacts with each of the donors $4-\mathrm{AB}$. 2- $\mathrm{AB}$ and $\mathrm{BD}$ in $\mathrm{CH}_{3} \mathrm{CN}$ at room temperature to form stable charge-transfer complexes. formulated as $1: 1$ ( $\mathrm{TCNQ}^{-\bullet} / \mathrm{D}^{-\bullet}$ ) in low donor concentrations. In high donor concentrations, TCNQ formed new colored complexes such as $2: 1$ (TCNQ ${ }^{2-}$ $/ 2 \mathrm{D}^{+*}$, which have an absorption band at around $500 \mathrm{~mm}$. These charge-transfer complexes clearly show absorption bands related to their ionic species. These results confirm that the CT process essentially involves the complete electron transfer from the donor to the acceptor. Upon irradiation, the formation of complexes progresses quickly, and no complexes reversibly fade. In this way, stable photoproducts could be efficiently formed through the photoinduced chargetransfer processes. We are extending our time-resolved spectroscopic studies to include systems which realize stable photoproducts.

Acknowledgements. This study was supported by research funds from Chosun University Korea (2007).

\section{References}

1. Foster. R. Organic Charge Transfer Complexes: Academic Press: London, 1969.

2. Mulliken, R. S.: Person, W. B. Molecular Complexes: Wiley: New York, 1969

3. Verhoeven. J. W. Pure Appt. Chem. 1990.62.1585

4. De Schryver. F. C.: Declercq. D.: Depaemelaere. S.: Hermans. E.: Onkelinx. A.: Verhoeven. J. W: Gelan. J. J. Photochem. Photobiol. A: Chem. 1994. 82.171.

5. Schön J. H: Meng. H.: Bao. Z. Nature 2001 $\$ 13.713$.

6. Cui, X. D.: Primak, A.: Zarate. X.: Tomfolur. I. Sankev. O. F.:
Moore. A. L.: Moore. T. A.: Gust. D.: Harris. G.: Lindsay. S. M. Science 2001. 294. 571 .

7. Metzger. R. M. Acc. Chent. Res. 1999. 32.950

8. Goes. M: Verhoeven, J. W: Hofstraat. H.; Brunner. K. Chem. Phus. Chem. 2003, 4. 349.

9. Wooster, T. T.: Watanabe, M.; Murray. R. W. J. Phws. Chem. 1992. 96.5886 .

10. Okamoto. K.: Ozeki. M.: Itaya. A.: Kusubayashi. S.: Mikawa. H Bull. Chem. Soc. Jpm. 1975. 48. 1362.

11. Pearson, J. M. Pure Appl. Chem. 1977. 49. 463.

12. Guillet, J. In Potymer Photophusics and Photochemistry th Introduction to the Study of Photoprocesses in Macromolecules, Cambridge University Press: Cambridge. U.K. 1985.

13. (a) Coleman. L. B.: Cohen. J. A.: Garito. A. F.: Heeger. A. I. Plns Rew. B 1973. 7. 2122. (b) Ferraris. S. P.: Cowant. D.: Walalka. V: Perlestein. J. H. J.Am. Chem. Soc, $1973,95,948$.

14. Kim. Y.-I.: Jeong. C.-K.: Lee. Y.-M- Choi, S.-N. Bull. Koram Chem. Soc. 2002, 23. 1754

15. Sein Tr. L. T.: Wei. Y.: Jansent. S. A. Snthetic Metals 2000. 108. 101 .

16. Egat1. H. Emirommental Carcinogens-Selected Hethods of Anohsis in Some Aromatic Amines and Azo dyes in the General and Industrial Enwironnent, LARC: Lvon. 1981; Vol. 4.

17. Sentchouk, V. V.: Grintsevich, E. E. Biochemisny (Aloscow 2004. 69.201.

18. Kadlular. F. F.: Fu. P. P.: Jung. H.: Shaikh. A. U.: Beland. F. A. Emiron. Healh Perspect. 1990. 87. 233.

19. Lai. D. Y.: Woo, Y. T.: Argus, M. F.; Arco, J. C. In Designing Safer Chemicals: Gren Chemisty for Pollution Prevention, ACS Symposium Series 640: DeVito. S. C., Garrett. R. L. Eds:American Chemical Society: Washington. D.C. 1996: pp 62-73.

20. Chen. S.-C.: Kao. C.-M.: Huang. M.-H.: Shih. M.-K.: Chen. Y.-L: Huang. S.-P.: Liu. T.-Z. Toxicological Science 2003. 72.283.

21. Jonkman. H. T.: Kommandeur. J. Chem. Phus. Lett. 1972, 15. 496

22. Jeanmaire, D. L.; Van Durne, R. P. J. Am Chem. Soc, 1976. 98. 4029.

23. Benesi. H. A.: Hildebrand. J. H. J. Am. Chem. Soc. 1949. 71. 2703.

24. Rehm1. D.: Weller. A. Ist J. Chent 1970. 259.

25. Rehm. D.: Weller. A. Ber: Bthsenges. Phus. Chem 1969.73,837

26. Yamaguchi. S.: Potember, R. S. Sunthetic Wetals 1996. 78, 117.

27. Wheland, R. C.: Gillson. J. L. J. Am. Chem. Soc. 1976. 98.3916. 